these vessels materially assists in effecting this change. As this view is almost, if not entirely, new, and would require an elaborate examination to establish its truth, I shall not dilate upon it here, but shall take it into consideration in connection with another subject, on which 1 am at present engaged.

There is another physiological fact tending to prove these positions: when the ductus choledochus is tied the chyle is clear, and contains only a small apparent quantity of free fatty matter. In consequence of this, it was supposed, by Tiedemann and Gmelin, that the bile was a solvent of fatty matter; but other physiologists have proved this opinion to be false, and the fact remains yet unexplained. In this case, then, from closure of the natural passage of the bile, congestion of the liver must ensue, and, in consequence, congestion of the spleen, whose veins empty themselves into the vena porta. Now the spleen being congested, its lymphatics acquire an increased action, and carry an additional quantity of fibrine to the lacteals; and, in accordance with the law which I have unfolded, the chyle must necessarily be clearer than usual, and contain less free oily matter. This congestion of the spleen also explains the pathological condition of leanness, whilst its atrophy, or absence, accounts for the excess of fatty matter in the tissues.

A German physiologist, whose name I cannot at this moment remember, has proved that oily matter combines with albumen (and collaterally with fibrine) by mixing them together; and he has observed that the albumen forms a pellicie around the oil globule; a circumstance that $I$ have also observed. I am, Sir, your most obedient servaut,

\section{Enfield, Middlesex,}

Dec. 6, 1842.

\section{FUNCTION OF THE SPLEEN.}

\section{To the Editôr of The LANCET.}

SIR,-I pass over, as childish and nonsensical, the allegation by $\mathrm{Mr}$. Stevens, that I read his paper hypercritically or inattentively, and at once address myself to the subject.

In my note of $J$ an. 15, LANCET, p. 623, I noticed one grand deficiency in Mr. Stevens' paper, the absence of any analysis, either sensual or chemical, demonstrating that the splenic rein contained arterial blood. Here is Mr. Stevens' reply, - " I took in several phials separate specimens of arterial and venous blood from a dog, as well as some from its splenic vein. There was not one surgeon to whom these were shown who did not judge the latter to be arterial blood." Now, whatever value might have attached to this mere visual examination (for it does not merit the name even of sensual analysis)

No, 1014 .
Mr. Stevens at once negatives by his repeated affirmations that it is not entively arterial blood, thus making the above $j u d g$ ment appear truly ridiculous. Mr. Stevens says, "The blood of the splenic vein is chiefly and essentially arterial, and would be wholly so but for the small portion of the residual blood of the splenic nutrition (by the vasa vasorum)." To this proposition $I$ have objected on sensual analysis, and again here object that the blood of the splenic vein is not chiefly and essentially arterial,- that it is greatly deficient in fibrine and the other: constituents of arterial blood,- - that, in short, it is the colouring matter of the blood in its primitive condition, first rendered susceptible of aeration in the liver.

Now, it will be seen, that my objection does militate in a grext degree against what Mr. Stevens has advanced, the amalysis of the contents of the splenic vein being the " experimentum crucis" by which Mr. Stevens' theory must stand or fall. And should no analysis of the above nature be offered to THE LANCET pending this discussion, I will use my endeavours to procure it the tirst opportunity from some philosophical chemist, competent to the task, and in that case will frankly forward the result to TuE LANCET.

With respect to Mr. Jackson's theory, that the spleen is an " assistant circulatory organ," I object that it has yet to be demonstrated that either the spleen, properly speaking, or its capsule, or the portal vein, possesses any vital contractility whatever; " and," says Mr. Jackson, " he who denies their vital contractility also denies their propulsive power" (LANCET, p, 89). I am Sir, your obedient servant,

Jan. 30, 1843.

Francis Eagle.

\section{To the Editor of The Lancet.}

Sir,-I hope you will believe me when $I$ assure you that $I$ have no desire to force my opinions upon any of your readers. I have merely ventured to give a short and, I fear, an imperfect detail of certain microscopic and anatomical experiments which seem to have discovered (to me most satisfactorily) the function of the spleen and the placenta; and the professional congratulations which I have received have led me to feel the more confident in this opinion. Perhaps I am wrong, and am labouring under a monomania. According to Mr. John Jackson's dictum (your correspondent of last week) I am decidedly so, in every essential particular but one; but yet none of Mr. John Jack . son's reasons for thus extinguishing me are exactly satisfactory to my mind.

Mr. John Jackson says that Mr. StevensFirst. "Is wrong in stating that 'the spleen comprises a mere congeries of capillary vessels,' for the spleen, we all know, is 
remarkable for its distensibility, which capillaries are not."

I was ignorant enough to suppose that capillary vessels often became distended and visible to the naked eye during congestion.

Secondly. "He is wrong, too, in stating that its capsule is a prolongation from the aponeurotic tissue of the diaphragm."

The fibrous tunic is very thick at the root of the spleen, passing directly into the aponeurotic tissue of the diaphragm, as a strong supporting ligament. This is plain in the sheep and in the ass.

Thirdly. That " he is equally wrong in supposing the placenta to be a double and deciduous body of capillaries between the uterine arteries and the umbilical vein, and the umbilical arteries and the uterine veins, and in believing that the blood not only passes from the mother through the placenta to the foetus, but also back from the foetus through the placenta to the mother; for if blood did reiurn from the fuetus to the mother, it is evident the terminal branches of the umbilical arteries in the placenta would not be continuous with the radicles of the umbilical vein."

Quite evident; and here I venture to say that it is not in the power of Mr.Jackson to bring me an injected placenta showing any proper communication between the umbilical arteries and what he calls the radicles of the umbilical vein.

Fourthly. "He is, moreover, wrong in the version which he has given of my theory as to the use of the spleen; for he appears to imagine that $I$ believe the spleen, per se, propels the portal blood through the liver; whereas I do not regard the spleen as an isolated organ, but as the roots of the splenohepatic vein, and that it is that vein which propels the blood through the liver."

I apologise for having done Mr. Jackson this injustice; but (excuse my ignorance) do the hæmorrhoidal veins form any part of the roots of this spleno-hepatic vein? And if so (as ${ }^{3} I$ suppose), do they belong to the spleen?

Fifthly. "But that in which Mr. Stevens is most wrong is in supposing the large size of the splenic artery is for the purpose of supplying a large quantity of oxygenised blood to the portal blood, or that the spleen is for the purpose of diverting arterial blood into the portal vein; for if it were so, the size of the splenic artery and the spleen would bear pretty nearly the same proportion to the liver in all animals, and would not be more than twice as large relatively to the liver in man as they are in the quadruped."

What quadrupeds has Mr. Jackson examined? I know of no such law applying to the whole class; and it varies greatly in fat and in lean men. But has Mr. J.taken any pains to examine the splenic blood as regards oxygen and carbonic acid?

Sixthly. "The reason the splenic artery is a large artery is because it is necessarily proportionate to the quantity of venous radicles of which the spleen essentially consists."

I was under the impression that the notion of venous radicles was exploded. The microscope has failed to define to me where the arteries cease, and where the venous radicles commence. They have always seemed to me to merge into one another, and to be directly joined.

Seventhly. "Mr. Stevens is right in remarking that no change is effected on the blood in its progress through the spleen, but in every other essential particular he is wrong. The last number of The LANCET contains a note from Mr. Eagle, in which he ob. serves that the blood in the splenic vein is neither venous nor arterial. Mr. Eagle is perfectly right there. The portal blood is ailuted blood, for every ounce of fluid received by the stomach passes into the splenic vein."

Pray, by what set of vessels does all the fluid received by the stomach obtain admission into the splenic vein?

Since all these points were fairly stated in my original paper, and since no experiments have been brought forward in opposition to mine, what can induce these gentlemen to go off at " half-cock," not having first duly considered what I have done and described? I remain, Sir, yours most respectfully,

Kennington, Jan. 28, 1843. Robert Stevens.

\section{DR. AYRES' REMARKS ON LIEBIG' VIEWS.}

To the Editor of THE LANCET.

S1R,-The note of your correspondent, "D.," at p. 440, (or, as I shall style him, Debilis, from the character of his remarks), would require no comment, were it not that some among your readers may have misunderstood both my reasoning and objects (p. 342). It is amusing to find the argumentum ad rerecundiam of the old logicians brought forward at the present day, when everything new is subjected to the most severe ordeal of discussion. Your correspondent appears to belong to the middle ages, and has constituted Liebig his Aristotle, to speak against whose opinions is heresy. His argument amounts to this : "Because Liebig's opinions have been subjected to the German physiologists and public and have been approved by them, therefore they are absolutely true!"

Your correspondent must certainly have misunderstood me in my argument as to the existence of both locomotion and sensible motion in plants and animals; for he seems to infer that I had taken up your space in the vain attempt to find an absolute distinction between the two kingdoms at their point of union. The fundamental axioms of Liebig on the distinction of motion in animals from 